\title{
Coming Together by Moving Apart: Contemporary Dance Scores and Communities During the Covid-19 Pandemic
}

Hetty Blades, Centre for Dance Research (C-DaRE), Coventry University

\section{Abstract}

This paper discusses Roof/Roof Piece, an adaptation of Trisha Brown's Roof Piece by Trisha Brown Dance Company and perch a dance made by Amy Voris and adapted by Voris and Katye Coe for Coe to perform in her home and online. Both these adaptations began during the Covid-19 pandemic, in contexts when the artists could not meet in person. I consider the role that the scores played in facilitating these shared practices, asking how they allowed for the development and continuation of bonds between members of dance communities during this period.

Keywords: scores, community, shared practice

A grid of nine small boxes fills my screen. In the box in the top left corner, a dancer raises both arms into a v before giving a small shunt and moving her arms to shoulder height, so they are parallel to the floor. She lifts her left leg and circles the hip before placing her leg back down and lowering her left arm. As the movement ripples through her body, it also travels across the screen. The dancer to her right follows each movement a pace behind. This is in turn followed by the next dancer along the top of the screen before snaking down to the dancer on the left of the row below, along that row and across the one at the bottom of the screen. The dancers are dressed in red. Each occupies a different place, and their surroundings are clearly visible. One dances outside on a wooden deck, with trees and fields in the background. Chairs, pictures, bookshelves and windows are visible in the rooms of other dancers, situating them within domestic spaces. They move together, despite being physically apart. The grid format is video calling platform Zoom's 'gallery view.' This organization of people in domestic spaces into a grid of boxes became an increasingly recognizable aesthetic during 2020, as Zoom and other video calling platforms became increasingly central to many people's interactions. The dancers: Cecily Campbell, Marc Crousillat, Kimberly Fulmer, Leah Ives, Amanda Kmett'Pendry, Patrick McGrath, Jamie Scott, Stuart 
Shugg, and Jacob Storer, are all members of Trisha Brown Dance Company (TBDC) and the work is a version of Brown's Roof Piece, during which dancers dressed in red perform on rooftops. The work was first performed in New York in 1971 then renamed Room/Roof Piece and reworked in 2020 to be danced at home. ${ }^{1}$

On another day, through the same screen, I watch as dance artist Katye Coe kneels on the floor of her daughter, Tala's bedroom and slowly folds at the waist. The camera zooms in on her hands as they trail across the floor and her torso moves towards the bed. In the background, Tala sits on her bed, looking at a laptop. Coe slowly pushes her own body onto the bed, folding smoothly into it and rolling across as she reaches for the wall. Here she pauses, her head resting against Tala's legs. During this moment of stillness, the bed clothes are in sharp focus in the foreground of the shot, with Coe's figure softened in the background. After the pause, she resumes movement, rolls swiftly off the bed and crawls backwards out of the room. I am witnessing perch, a dance made by dance artist Amy Voris between 2014-19 and adapted for Coe to perform in her house and online during the Covid-19 pandemic.

In many countries, much of 2020 was lived under 'lockdown,' or some form of restriction on in-person interactions. For example, under the strictest period of lockdown in the UK where I am based, face-to-face interaction was allowed only in exceptional cases and following this, only while following social distancing guidelines. One result of these rules is that dance artists, students, teachers and audiences had to develop and adapt ways to continue to train, make, perform and watch dance, often relying on the internet to facilitate exchanges. While internet practices for dance are by no means new, they have been relied upon, developed and adapted in new ways during this time. Both Room/Roof Piece and perch are versions of works that pre-existed the pandemic, but that were adapted and re-performed during this period. Although very different in many ways, Room/Roof Piece and the adaptation of perch both use scores as a means to share and adapt the works. In this paper, I analyze the role that the scores played in facilitating these shared practices during lockdown and in enabling the formation and continuation of bonds between members of dance communities while they could not meet in person.

'Community' is a term that has slightly different connotations in different contexts. ${ }^{2}$ What a social group-including a community-is, whether it exists, how it comes into existence, how it is maintained, and its norms of practice are areas examined in the field of social ontology. ${ }^{3}$ In the UK, 'dance community' is a term that is commonly used to describe an amorphous collection of people associated with the form in various ways. Social groups can often survive changes to their membership 4 and this appears to be a key feature of the dance community, as it is not defined by or dependent upon any particular person or people. Although the term 'dance community' is commonly used to refer to a single, albeit amorphous group, there are multiple communities within the over-arching group. ${ }^{5}$ Jasmine Hearn, a dance artist based in New York who I interviewed in 2018 described "a lot of communities that intersect with one another." ${ }^{6}$ For example, 
these might revolve around certain fields of practice, geographical locations, shared social or cultural experiences, or particular institutions. Writing about the notion of community in relation to dance, 'Funmi Adewole suggests,

'[c]ommunity' is a complex and layered term, meaning different things in different places. A factor that seems to be common to most definitions of community is that a community consists of people [who] are considered to be a collective, but this could be on the basis of shared background, heritage, experience, or circumstances. I would like to add the caveat that my descriptions of community should not be taken as being a sociological proven fact but as a banner under which to discuss good practices. ${ }^{7}$

As previously mentioned, some communities arise through shared practices. ${ }^{8}$ Educational theorist and practitioner Etienne Wenger suggests such groups can be understood as 'communities of practice.' Wenger describes communities of practice as "formed by people who engage in a process of collective learning in a shared domain of human endeavour." ${ }^{9}$ This is a concept discussed by Adewole in relation to dance. Writing in 2011 she describes how the discourse surrounding African People's Dance (APD) and Black dance in the UK at this time had undergone a shift away from a focus on developing infrastructure and debates about terminology and that "[m]ore critical attention is given to the cultural and artistic value of the work being produced by dancers." 10 She describes a conversation with Jeanette Bain-Burnett, who was at that time the director of Association of Dance of the African Diaspora prior to an event called African Dance Encounter:

She told me that one of the aims of the event was to encourage discussion and exchange between artists and promote a 'community of practice' within APD. For me this is an exciting proposition. Practitioners older than me might say this has echoes of how the sector saw itself when it first became visible in Britain. ${ }^{11}$

In a more recent article, Adewole returns to the notion of community of practice, exploring three different conceptions of community: community dance, communities that dance, and communities of practice. ${ }^{12}$ In relation to communities of practice, she writes: "Presently, we are witnessing a growing number of artists who run initiatives which promote this kind of community sharing, ${ }^{113}$ and refers to dance artist Alesandra Seutin's workshop program for dance practitioners at Ecole des Sables in Senegal as an example of this. Seutin's program "brought dancers from several nations around the world who are invested in the dance of Africa and the Diaspora to learn, experiment, discuss and experience the practices of a cohort of internationally recognised teachers." ${ }^{14}$

In what follows, I consider how Room/Roof Piece and the adaptation of perch highlight communities of dance practice that were formed and/or maintained during the pandemic. I do not argue for the existence of a single dance community, but instead 
focus on these two specific examples of community. Writing about her research into the "Brussels dance community" Eleanor Bauer describes how some interviewees suggested that "community does not exist in the Brussels dance field." ${ }^{15}$ There is indeed some important thinking to be done about whether dance communities exist at all. However, full consideration of these issues is beyond the scope of this paper. Rather, I analyze how movement scores functioned to underpin shared practice and therefore maintained community ties during a period of time while most interactions took place online. I draw on Harmony Bench's articulation of the way that dance-media facilitates and makes visible acting "in common" to consider how it is that scores facilitate shared practice. ${ }^{16}$ Extending Wenger's suggestion about the shared domain of communities of practice, I draw on Alessandro Salice's reading of Dietrich von Hildebrand, ${ }^{17}$ to describe how movement "in common" can generate a shared axiological domain and propose that through shared practices, shared values play a role in the formation of dance communities.

Both Room/Roof Piece and perch are positioned within the field of contemporary theater dance. The term 'contemporary dance' is loosely applied across a range of distinct but overlapping genres and styles of dance ${ }^{18}$ and talking about contemporary dance in general terms can be problematic. The term 'contemporary' when applied to dance has an association with the West and can therefore be a mechanism for exclusion. ${ }^{19}$ Dance and performance scholar SanSan Kwan reminds us that "it is important to remember the fraught nature of temporal terms such as 'contemporary' and 'modern' and the ways that they are often linked with the geographical and cultural, that is, with the West." ${ }^{\prime 20}$ Kwan discusses how the term contemporary applies in relation to concert, commercial and world dance. The examples I discuss originate from lineages associated with contemporary concert dance, also referred to as theatre dance. ${ }^{21}$ Kwan highlights how in this context, the term contemporary dance refers to a range of forms which "might include release technique and/or contact improvisation (sometimes considered the techniques of postmodern dance), floor work, various modern dance techniques (i.e., Graham, Limon, Horton, Hawkins, or Cunningham), and/or ballet. Increasingly, contemporary dance draws on non-Western forms (i.e., African and African diasporic dance, Asian martial arts, yoga) and street dance forms." ${ }^{22}$ I use the term 'contemporary theatre dance' in this paper in order to situate the examples I describe as, broadly speaking from within this field but acknowledge that this term refers to a much broader array of practices than I discuss here.

Scores

In some areas of contemporary theatre dance, the term 'score' might refer to records of movement inscribed through codified notation systems such as Benesh, Labanotation or Beauchamps-Feuillet, or to a wider variety of mental, verbal or written entities which might be shared or private. ${ }^{23}$ When scores are written documents, they might take the form of words, diagrams or drawings. Approaches to scoring are often idiosyncratic to 
particular artists. ${ }^{24}$ While some choreographers use scores to determine a work's specific movement, others utilise the potential ambiguity of language in order to develop scores that are consciously non-didactic. The latter approach is described by dance scholar Alison D'Amato as "indeterminate language scores." ${ }^{\text {" } 5}$ She writes, "[t]he creator of an indeterminate score intentionally bends notation towards unpredictability, putting forward signifiers that effectively correspond to a multiplicity of corporeal signifieds," ${ }^{26}$ thus highlighting how scores can be generative and open to multiple different interpretations. ${ }^{27}$

Anna Pakes acknowledges the breadth of the term score in relation to contemporary theatre dance: "Sometimes, the term score is used broadly in contemporary practice to mean the very structures or norms of a choreographic performance, rather than their representation. ${ }^{\prime 28}$ Despite being a broad concept, scores have some unifying features. Bench includes scores in her description of embodied objects suggesting that these are "nonmaterial, corporeal objects that assume a bodily shape or sequence, and are transferable and transmissible across the bodies that are their primary medium. ${ }^{29}$ She draws on Michel Serres' concept of "quasi-objects" to elaborate her account of "embodied objects," pointing out that a quasi-object is one that only makes sense when it is activated in movement. ${ }^{30} \mathrm{~A}$ score then is a set of parameters which may or may not manifest as a concrete object, but even when it does, it is only truly manifest via activation through movement.

Pakes describes how: "Postmodern dance artists have developed and employed verbal documents, collections of images, diagrams, and other textual materials to communicate more 'objectively' with dancers, liberate performers' creativity, and encourage decision making in the moment of performance." ${ }^{31}$ This focus on the performers' autonomy that is facilitated through the use of scores offers a key distinction between a score and the sharing of a work or practice through physical demonstration and copying. For example, in online video tutorials such as Re:Rosas, ${ }^{32}$ in which Anne Teresa De Keersmaeker and Samantha van Wissen teach the movements of part of De Keersmaeker's work Rosas danst Rosas (1983) and Learn the Nelken-Line, ${ }^{33}$ in which Julie Anne Stanzak teaches the movement for the 'Spring, Summer, Autumn, Winter' line in choreographer Pina Bausch's work Nelken (1982), the movements from the works are demonstrated by performers for viewers to copy. While these sections of the works might be underpinned by a score, the video tutorial format demonstrates a different way of communicating the principles of the work, which relies on the person embodying the instructions copying movements, rather than interpreting a score. ${ }^{34}$

While scores are important to many areas of dance practice and are by no means a recent phenomenon, the move online that occurred during the Covid-19 pandemic highlighted their potential for instigating shared experiences through movement. Several companies, artists and organizations published scores online as a means through which to engage people in dance and movement. Examples include: Perform It Yourself Scores, published by $\mathrm{iii}^{35}$ which is a collection of scores from various artists 
working in different disciplines that people can perform at home; choreographer Yvonne Rainer's adaptation of part of her 1963 work Terrain renamed 'Passing and Jostling while Confined to a Small Apartment' and published by Brian Seibert in The New York Times; ${ }^{36}$ Detour Dance's Jukebox which offered a series of prompts for artistic response. ${ }^{37} 26$ choreographic scores have also been commissioned by University of California Los Angeles' Centre for the Art of Performance as a way of investing in the future of dance. Choreographers have been asked "to create a dance score for a future project while they await their return to the studio and stage: each one a love letter to the future of dance." ${ }^{\prime 38}$

\section{Room/Roof Piece}

The description that opens this article is of an excerpt of Room/Roof Piece which was released on YouTube. In the full version, published on the TBDC website, the audiences also see the start of the piece, during which the dancers each turn on their camera and step back, establishing themselves in place, at home. The dancers join one at a time. The first movement is a wave, repeated by each of the dancers. This movement establishes the logic of the work, during which one person leads a sequence of movements and each performer copies the dancer who precedes them.

The full-length version is edited so that the focus moves between dancers, rather than showing the whole grid for the entire time. As a single dancer fills the screen, the detail of the movement becomes more visible. The fluid articulation of body parts that characterizes much of Brown's work is foregrounded by the closeness of the camera to the dancers' bodies. As the screencast switches between viewing a single dancer and the group as a whole, my attention moves between the detail of the movement and experiencing the collective action and embodied logic of the score.

The dancing is accompanied by the sounds of each performer's surroundings and of their movement. I hear breathing, bird song, an engine passing. At times there is interference on one of the dancer's microphones, causing a wind-like sound. The image quality on the film differs between dancers, perhaps dependent on the effectiveness of their internet connection. The image is sometimes blurred and the pixelation causes me to exit full-screen mode, embedding the video back into the TBDC website to try and get a clearer view. Dance critic Brian Seibert points out that the dancers must face the screen and that adaptation required some new choreography related to the online transmission format. ${ }^{39}$ The way that dancers must pick up their cues from their screens means that they don't look directly at the camera, but just below it, which keeps their gazes from meeting that of the spectator. The position of the screen seems to vary slightly between dancers, with some having a lower focus than others. This combination of the domestic surroundings, just off-camera gaze, sound interruption and pixelation create an aesthetic that arises through the use of screen casting video calling platforms as a means to record and transmit dance. In the case of TBDC's Room/Roof Piece there is 
a layering that occurs between the aesthetics of the movement, the precision and fluidity of the articulations in the bodies of the dancers, and the disrupted, interrupted, pixelated and off-center aesthetics of the screencast. Furthermore, I witness a temporal layering, as the movement in the bodies of the dancers, enacting a work from the 1970s, makes me think about images of the work I have encountered in the past, reminding me of the consistency of practice through time and across geographical locations.

Describing the earlier version of the work, Brown writes:

Simple, semaphor-like movement (joint articulation and perpendicular and parallel lines) was continuously transmitted from one dancer to another, each stationed on separate roofs, spanning a nine to twelve block section of New York City [...]. After fifteen minutes, the sender ducked out of sight to indicate by pre-arrangement that she had finished. All dancers turned to face in the opposite direction and the receiver became the sender reversing the flow of movement across town for an equal duration of time. Part of the audience was placed on a roof midway between White Street and West Broadway (building 35). Another group was at the end of the dance (building 64), and a third audience was comprised of uninformed people in the neighborhood whose eyes stumbled accidentally upon one or more links in the event. ${ }^{40}$

This description of the work as performed on the roof tops of New York City foregrounds the organizing principles of the work and the way that pre-agreed rules or cues structure the transmission of movement between the performers. According to Pakes, ${ }^{41}$ agreements between people have an important role in the making and instantiation of dance works. Sharing aspects of a work or practice via scores might allow for some of the principles to be enacted without verbal or physical direction from previous performers. However, it's important to note that scores are often used alongside other forms of agreement in the process of enacting a work or practice. ${ }^{42}$

The adaptation of Roof Piece was reported on by Seibert in The New York Times on 7 April 2020. His article includes the following directions, offered by the company to enable people to make their own versions of Room/Roof Piece:

First, invite some friends to a meeting on a videoconferencing platform. (The dancers used Zoom.) Then choose the order of transmission: who is leader, who is No. 2, No. 3 and so on.

The leader starts with a simple greeting, a wave of the hand. The rest of the motions are up to you, whatever you think "semaphore-like" means. ("Joint articulation and parallel and perpendicular lines," Brown further specified.) A deep squat is the signal for the last person in line to take over as leader, reversing the flow. When that new leader wants it all to end, another squat is the sign. ${ }^{43}$ 
This score comprises a short set of fairly loose instructions. The movement style is shaped by quoting Brown's description of the action, and the cue described by Brown of the sender ducking out of sight to signal that it's time to reverse the order has been replaced with a deep squat. While Seibert quotes Brown, the score is nevertheless his paraphrasing of the instructions from TBDC for the work. Seibert also invites people to post a link to themselves performing the work in the comments, stating that these might be featured in a future article, ${ }^{44}$ thus the transmission and re-embodiment of Room/Roof piece is mediated through Seibert's paraphrasing of the score and The New York Times site. However, to date there are no links to performances of the score in the comments on the site.

Dance artist Malaika Sarco-Thomas accepted the invitation to enact the score and instigated a version of the work through A Class for a Cause. ${ }^{45}$ She interpreted the score in collaboration with Sara Reyes Acosta and Lucija Grbic. As the film starts, all three performers are close to the screen, turning on their cameras. They move back into position, waiting for the music they have chosen to start. Each moves subtly so that they are side-on to the screen but faced slightly towards it. The performer in the top left of the screen initiates the movement. As she turns away from the screen, free to look wherever she likes as she has no cues to follow, we see the two performers following her negotiate their own relationship to the screen. As they face directly away from the screen their heads rotate towards it in order to be able to see the next cue. The general aesthetic is similar to the TBDC film. The quality of the images is varied, with some pixelation. The camera angles are lower in this film, as though the performers' devices are placed on the floor and we cannot see the performers' faces clearly, but the sense of attention towards the screen, rather than the camera is noticeable. The domestic surroundings are clearly visible.

This version is posted on YouTube, ${ }^{46}$ rather than submitted to The New York Times. YouTube also hosts versions by Dakini Dance ${ }^{47}$ and Drouin Dance Center ${ }^{48}$ as well as another version instigated by Sarco-Thomas with University of Chester undergraduate dance students. ${ }^{49}$ Much of The New York Times is behind a paywall and the suggestion to post versions online raises questions about who stands to benefit financially from these renditions. The posting of the recordings on YouTube can be said to in part disentangle the renditions of the work from the mediation of The New York Times, although of course similar questions about potential revenue can be asked of YouTube.

The transmission of movements from one dancer to another demonstrates the connections between them and their shared intention to enact the score. I suggest that there is also a relation formed between these performers and the TBDC performers. Sarco-Thomas is dressed in red, although Acosta and Grbic are not, which forms a visual link to both Roof Piece and Room/Roof Piece. Furthermore, through the enacting of the score the performers are entering into relations with others who have danced the work. In this example, the connection between Sarco-Thomas, Acosta and Grbic, and the 
dancers of Brown's original work is facilitated through the sharing and enacting of the score online.

Bench proposes that dance offers "powerful physical articulations of how we act in common" 50 and that this acting in common is revealed and extended through the potentials of digital media. She writes that dance-media "not only make visible the ways we already move together and act in common in an era of computing and information globalization but also craft new possibilities through their specific combinations of bodily expression and digital cultural production." ${ }^{51}$ Bench's view of the commons draws together the associations of the term with both shared resources and as a shared orientation. ${ }^{52}$ For Bench, dance's circulation through digital media enables artists to make-common through participatory processes, and common dimensions of public spaces to be activated as well as facilitating "the sharing of a corporeal common of movement and gestural resources that circulate across dancers' bodies." ${ }^{33}$ She draws on Jean-Luc Nancy's work to elaborate the nature of acting or being in common. Articulating Nancy's perspective, Bench writes:

that there is only a 'we,' and that this 'we' is not a question of 'cohabitation or contamination' and especially not of communion but of ontology. This being-with is not manifested in adjacency, proximity, or shared space but is a relation without relation, an in-common that is not a common being, as though community were identical to consensus. The in-common is a shared sense that links or 'enchains' as world. ${ }^{54}$

The reworking, scoring and embodiment of Room/Roof Piece offers a rich example of Bench's perspective by both enabling participation and contributing to the "corporeal common." Furthermore, the score's publication facilitates people moving "in common" and reveals relations that "enchain" people through dance without "adjacency, proximity, or shared space." Relations occur both in the moment of dancing and through time, as the score also enables people to enter into relation "without relation" as they act "in common" with those who have previously danced the work.

perch

Voris describes perch as "a solo dance about temporary states and locations and the movement in-between these things. It is about the process of homing while feeling haunted by the past. First and foremost however perch is a practice, performed regularly by one person, for a place. ${ }^{155}$ It was made over a period of four years and approximately 120 practice sessions ${ }^{56}$ and first performed in Voris's studio in Manchester, UK. Starting in March 2020, during the UK's first period of lockdown, Voris and Coe undertook a series of 30-40 rehearsals, primarily online, with the aim of adapting Voris's score for perch for Coe and her home in Kenilworth, UK. perch was later performed by Coe for one or two audience members as a time, who followed her as she moved through her house and garden. 
The work was also adapted for online screening. Attending an online event, I wait on the Zoom landing page. After a few minutes the blank screen is replaced by a dark scene. Coe stands outside her house in the dark. The lit windows are visible behind her. It's hard to make out her features. Coe leads us into the house and sits down. She explains the history of perch, and what will happen during this performance. She then posts a link in the Zoom chat to a recorded film of the work shot by Christian Kipp in a single take, on a hand-held camera. Coe describes how if this were a live performance she would now put on a pair of pink earrings, taking them from a pocket and putting them into her ears as she speaks, playing with the distinction between this online version and the 'live' one. We are told to keep our Zoom connection running while we watch the recording and to come back together afterwards, turning on our cameras to signify that we have finished watching.

Coe moves through the different rooms of her house, starting at the top of the house in Tala's bedroom, as I previously described. Following this, Coe moves to the bathroom and her own bedroom before taking us downstairs to her living room, kitchen and garden. The focus of the camera moves between close ups of Coe's body parts as they connect with the surfaces of her house and zoomed out capture of the whole space that she inhabits. As with Room/Roof Piece, the adaptation of perch takes place in a domestic setting. However, rather than the house being a backdrop to the movement, it is a central part of the work. As Voris makes clear in the description of the work above, perch is performed "for a place," meaning that the relationship between the movement and the place it is performed is central to the practice. As my opening description shows, Coe's movement is entirely entwined with her surroundings.

The systematic way that Coe travels through the house from top to bottom and then into the garden appears to indicate a pre-defined structure for the work. It does not have the purely spontaneous feel of an improvised work, yet there is an emergent quality to Coe's movement that implies to me that the movements themselves are not entirely determined in advance of the performance. The fluid dynamics and focused quality of attention I witness from Coe suggests to me that the form of the movement is in a state of emergence, as opposed to being repeated exactly from previous performances either by Coe or Voris. However, when I later watch a footage of perch performed by Voris, ${ }^{57}$ I notice that some movement content between Voris's and Coe's versions overlaps. It seems then that the emergent quality of the movement then is part of the practice of perch rather than indicating that movement is entirely improvised in performance. 

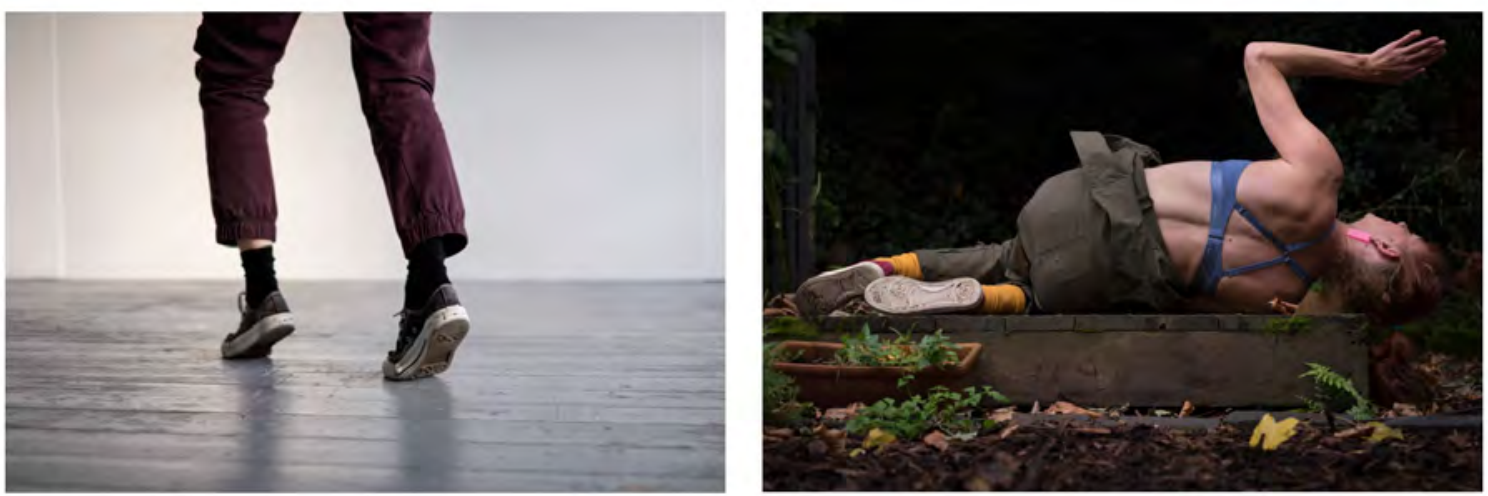

Image: Voris (L) and Coe (R) performing perch. Photos by Christian Kipp. Used with permission.

The score for perch was developed iteratively over Voris's long making process. ${ }^{58}$ She describes the score as being underpinned by a set of "processual qualities" which she articulates in her research in relation to the contemplative practice of Authentic Movement. ${ }^{59}$ The score, published in Voris's PhD thesis, is titled a "poetic score" ${ }^{160}$ and is perhaps indicative of such processual qualities in its written style ${ }^{61}$ that is akin to other forms of "indeterminate language scores" 62 in the way that the prompts are nondidactic.

The score begins:

[seahorse sidestep]

sideways

stepping

mapping

internal

readying

listening to the

intricacies of 
sound

deep

abdominals

responsiveness

in

legs

breaking

up

ground $^{63}$

While this version of the score definitely informed the adaptation, Voris suggests that the practice of perch itself rests on its changeability and adaptability. ${ }^{64}$ Coe describes how the score for the adaptation has been "permeated" with the conditions, ways of relating and systems of working between her and Voris. ${ }^{65}$ The score expanded through the process to encompass these aspects of working together. ${ }^{66}$

Coe and Voris discussed with me how they undertook the adaptation and the role of the score in this process. Voris described how each rehearsal involved a "warm-up preparatory activity" prior to working on the score. These activities were concerned with creating a shared space between Voris and Coe and that once this had been established, she felt very connected to Coe. Following this process, they would start working on adapting the score. ${ }^{67}$

While establishing the conditions for the practice was key, the score was also central to the project, in particular because of the conditions of lockdown. Coe describes how the existence of the score enabled the project to happen. They had been discussing working on something new, but didn't feel that it was possible during lockdown, whereas adapting an existing score and methodology gave them something solid to work with. ${ }^{68}$ Furthermore, Voris suggests that working only with processual qualities in order to develop a new work from scratch was too open for remote working, ${ }^{69}$ so although the score had originally been intended only as a tool for her, it became key to enabling the adaptation. ${ }^{70}$ The perch score then facilitated the adaptation between Voris and Coe, allowing them to enter into a shared practice. 
When the recording finishes, I retrieve the Zoom window from the bottom of my screen and turn on my camera. Slowly the other audience members return to the call. Coe and Voris talk about their experiences of the adaptation and answer questions from the audience. The hybrid mode of sharing perch through both live interaction and a recorded film also enabled a sense of community between the audience members, as we were part of a shared experience. Furthermore, it facilitated a different connection to Coe in performance than I experience when watching the recorded version online outside of the performance setting. These observations echo Hearn's description of how through the shared experience of live performance, people can build community, networks or memory together. ${ }^{71}$ The online screening of perch is particularly interesting as it arose only out of the conditions of lockdown. Voris states that the work was made to be witnessed live but that they decided to try the online streaming and both she and Coe describe how they felt nervous about sharing the work online. ${ }^{72}$ It therefore offers a pertinent example of the way that the lockdown gave rise to the sharing and adaptation of offline practices in new forms.

As previously mentioned, scores can be externalizations of some of the principles of a work. However, when performers enact a score but there are likely other agreements that need to take place before the work can be fully realized. ${ }^{73}$ Recent scholarship in dance has drawn attention to the role of these agreements, ${ }^{74}$ as well as joint commitment in dancing together ${ }^{75}$ and intention and action in dance. ${ }^{76}$ Furthermore, prominent views in social ontology see shared intention or intentional action as central to the constitution of social groups. ${ }^{77}$

However, Alessandro Salice explains how philosopher Dietrich von Hildebrand draws attention away from the relevance of shared intention within social groups, in particular in relation to communities. He explains Hildebrand's position: "instead of looking for the internal and subjective conditions that regulate the group's constitution, he rather stresses an external one, i.e., the "'virtus unitiva' or the unifying virtue that values can exert over individuals and which might bring them to constitute a group." 78 Salice summarizes how values act in the constitution of communities:

if a number of persons is working on the same problem, feeling its value, then they are incorporated in the same value or the same axiological domain and, hence, they are already unified. Such constitution proceeds by means of ontological necessity and does not rest upon the individual awareness of being a member of a group (howsoever this may be conceived). If, due to some psychological circumstance, the individuals come to be aware of each other, then the objective existence of the group starts to be accompanied by such awareness, and the group can act as a group. ${ }^{79}$

As with Wenger's description of communities of practice, a shared domain features in Salice's description. However, Salice stresses the role of values within this domain, how a shared goal has a particular value, and it is sharing the experience of this value, or 
entering the same 'axiological domain' that unifies people, whether or not they are aware of each other. ${ }^{80}$ The idea of being incorporated into a shared axiological domain helps us to understand more about how it is that communities might form. For example, we might think of the conditions generated through Voris and Coe's warm-ups, as the two of them cultivating a shared domain, not only of practice but also an axiological domain, leading to the sense of connection described by Voris. ${ }^{81}$ Furthermore, this explanation further sheds light on how the performers of Room/Roof Piece might be drawn into relations with other people enacting the score or performing Roof Piece at different times, as they all can be said to share an axiological domain without necessarily being aware of one another.

According to Salice, Hildebrand "weakens the relevance that contemporary debate ascribes to the notion of shared intention and shared agency" by suggesting that values, rather than shared intention can constitute communities..$^{82}$ In relation to these two examples, I suggest that the score offers a concrete focus for the shared intention to practice together, but that the practice gives rise to a shared axiological domain, meaning that the values that arise through enacting the score underpin the connections between people that arise when they dance "in common." ${ }^{83}$ Because a score is an embodied "quasi-object," 84 it is the enacting of the score, rather than the thing itself that incorporates people into a shared axiological domain.

\section{Concluding thoughts}

The online circulation of Room/Roof Piece and perch resonate with Bench's articulation of the way that dance-media both enables and makes visible movement "in common." ${ }^{185}$ Bench describes how reproducing gestures can "articulate a form of gestural belonging" and "offer a shared sense that gives meaning to a common world supportive of social or communal interaction." ${ }^{86}$ These scores allow for the transmission and adaptation of dance works and practices through instruction that can be interpreted by each artist or group of artists who choose to enact the score. This process can be understood as giving rise to a sense of "gestural belonging," despite gestures not being replicated exactly between renditions of the works. Furthermore, these scores function as externalizations of some aspects of the agreements that can underpin dancing "in common."

The examples I have examined here demonstrate different ways of being in relation to others. The Room/Roof Piece score enables people to embody this part of the work and for performers to dance "in common" with each other in the moment of performance, through the shared intention to enact the score and the copying of each other's movement. Furthermore, this process draws performers into relation with others who have performed both Roof Piece and Room/Roof Piece. On the other hand, perch is a solo, but the adaptation involved a collaborative process in which Voris and Coe worked alongside. Through the adaptation and enacting of the score, Coe and Voris acted "in 
common" and entered a shared domain even though they don't perform together in the work.

Scores are frequently used some areas of contemporary theatre dance. However, these scores played a particularly important role during the Covid-19 pandemic by enabling the formation and continuation of shared practices. I am not suggesting that it is only through scores that people dance "in common" or form dance communities, but that in these cases, turning to scores productively enabled artistic collaboration during lockdown. By "acting in common"87 through the embodiment of these scores, the artists can be said to enter a shared domain of practice, or "community of practice." 88 I suggest that, following Salice, this domain might also be understood as an "axiological domain" 89 in which people are drawn into relation through the value of a shared goal and that these relations might be understood as a form of what Bench terms "gestural belonging. ${ }^{\prime 90}$ The value that arises through the adaptation and embodiment of these scores can be seen as key to forming and maintaining bonds between members of these dance communities.

\section{Biography}

Hetty Blades is Assistant Professor in the Centre for Dance Research (C-DaRE) at Coventry University. Her research focuses on dance's documentation and transmission through digital technology and dance, disability and human rights education.

Email: hetty.blades@coventry.ac.uk

\section{Notes}

${ }^{1}$ The project was conceived, produced and edited by Amanda Kmett'Pendry and Jamie Scott. See: https://trishabrowncompany.org/news/

${ }^{2}$ Adewole, "The Concept of 'Community' and 'Professional' Dance," 9.

3 See for example Thomasson, "The Ontology of Social Groups" and Salice, "Communities and Values." 
${ }^{4}$ Thomasson, "The Ontology of Social Groups," 4833.

${ }^{5}$ See also Bauer's discussion of sub-communities, "Becoming Room, Becoming Mac," 64.

${ }^{6}$ Hearn, interview with author.

${ }^{7}$ Adewole, "The Concept of 'Community,'" 9.

${ }^{8}$ See Bench, Perpetual Motion, 6. Bench cites Judith Hamera, Dancing Communities in regard to the relationship between communities and shared practices.

${ }^{9}$ Wenger, "Communities of Practice," 1.

${ }^{10}$ Adewole, "More Conversations Please!," 10.

${ }^{11}$ Ibid. 12.

${ }^{12}$ Adewole, "The Concept of 'Community.'"

${ }^{13}$ Ibid. 10.

${ }^{14}$ Ibid.

${ }^{15}$ Bauer, 62.

${ }^{16}$ See Bench.

${ }^{17}$ Salice. To my knowledge, the Hildebrand text that Salice examines in not available in English, hence my decision to refer to it via Salice. Following Salice, I refer to von Hildebrand as Hildebrand throughout.

${ }^{18}$ Kwan, "When is Contemporary Dance?"

${ }^{19}$ lbid. 38 and 47.

20 lbid. 44-45.

${ }^{21}$ See Pakes, Choreography Invisible, 1.

${ }^{22}$ Kwan, 40.

${ }^{23}$ See Millard, "What's the Score" who discusses the use of the term 'score' to refer to verbal prompts in her improvisation practice.

${ }^{24}$ See Burrows, A Choreographer's Handbook and Van Imschoot, "Rests in Pieces."

${ }^{25}$ D'Amato, "Performing Interpretation." 
${ }^{26}$ Ibid. 53.

${ }^{27}$ Much of my previous writing has also considered the nature of dance scores. For example, "Scoring Choreographic Poetics," "Scoring Dance," and "Affective Traces in Virtual Spaces."

${ }^{28}$ Pakes, 137.

${ }^{29}$ Bench, 161.

${ }^{30}$ Ibid.

${ }^{31}$ Pakes, 137.

32 See Re:Rosas, accessed 31 January 2021: https://www.rosasdanstrosas.be/en-home/

${ }^{33}$ See "The Nelken Line by Pina Bausch," YouTube, uploaded 2 August 2016, accessed 31 January 2021: https://www.youtube.com/watch?v=MZI4cgGRhzE

${ }^{34}$ In a previous chapter, "Preservation and Paradox" I argued that Re:Rosas could be understood as a score. However, I have revised that view here and suggest it demonstrates a different mode of transmitting the work.

${ }^{35}$ See "PIY Scores - Active Home Entertainment for the Curious," accessed 31 January 2021: https://instrumentinventors.org/production/diy-scores/

${ }^{36}$ See Seibert, "A D.I.Y. Dance for Your Home, From Yvonne Rainer."

37 See Detour Dance, "Jukebox."

38 See UCLA Center for the Art of Performance, "The Choreographers' Scores 2020," accessed 31 January 2021: https://cap.ucla.edu/calendar/details/scores

${ }^{39}$ Seibert, "A Home Version of Trisha Brown's Roof Piece."

${ }^{40}$ Brown, "Three Pieces," 26.

${ }^{41}$ Pakes, 134, 137.

42 Van Imschoot; Pakes, 137.

${ }^{43}$ Seibert, "A Home Version."

${ }^{44}$ Ibid.

${ }^{45}$ A Class for a Cause is an initiative led by Eleanour Bauer and Leah Landau through which artists can share practices and classes online in exchange for donations for social 
causes or their own income. Petitions and actions can also be suggested instead of donations.

${ }^{46}$ See Sarco-Thomas et al., "Room/Roof Piece by Zoom."

47 See Dakini Dance, "Room/Roof Piece by Dakini Dance."

${ }^{48}$ See Drouin Dance Center, "Drouin Dance Center's Version of Room/Roof Piece."

49 See Sarco-Thomas et al. "Room/Roof Piece with University of Chester BA Dance Students."

${ }^{50}$ Bench, 3.

51 Ibid. 4.

52 Bench draws on the work of Ramsay Burt and Elizabeth Dillon to elaborate her position. Bench, 8 .

53 Ibid. 9.

${ }^{54}$ Ibid. 118. The quotes within this quote are from Nancy's Being Singular Plural, 43.

${ }^{55}$ Voris "perch": https://www.amyvoris.com/perch/

${ }^{56}$ Voris, "Forming , Returning and Deepening," 30.

57 See Voris "perch."

${ }^{58}$ Voris, interview with author.

${ }^{59}$ Voris in written exchange with author.

${ }^{60}$ Voris, "Forming," 158.

${ }^{61}$ Voris in written exchange with author.

${ }^{62}$ D'Amato.

${ }^{63}$ Voris, "Forming," 158.

${ }^{64}$ Voris in written exchange with author.

${ }^{65}$ Coe, interview with author and Voris in written exchange with author.

${ }^{66}$ Ibid.

${ }^{67}$ Voris, interview with author. 
${ }^{68}$ Coe, interview with author.

${ }^{69}$ Voris in written exchange with author.

${ }^{70}$ Voris, interview with author.

${ }^{71}$ Hearn, interview with author.

${ }^{72}$ Voris and Coe, interview with author.

${ }^{73}$ Van Imschoot; Pakes, 137.

${ }^{74}$ Pakes.

${ }^{75}$ Vidrin, "Reasoning in Relation."

${ }^{76}$ McFee, Dance and the Philosophy of Action. Pakes discusses the possibility that dance works are structures of action in Choreography Invisible.

77 Salice, 238.

78 Ibid. 237.

79 Ibid. 252.

${ }^{80}$ Vidrin also considers the role of value and values in his study of partnering, but with a greater focus on evaluation and value systems.

${ }^{81}$ Voris, interview with author.

${ }^{82}$ Salice, 237.

${ }^{83}$ Bench, 3.

${ }^{84}$ Ibid. 161.

${ }^{85}$ Ibid. 4.

${ }^{86}$ Ibid. 161.

${ }^{87}$ lbid. 3.

${ }^{88}$ See Etienne Wenger "Communities of Practice: A Brief Introduction" and 'Funmi Adewole, "More Conversations Please!" and "The Concept of 'Community' and Professional Dance."

${ }^{89}$ Salice, 252. 
${ }^{90}$ Bench, 161.

\section{References}

Adewole, 'Funmi. "More Conversations Please!" Animated (Spring 2011) Accessed 10 Jan. 2021. https://www.communitydance.org.uk/DB/animated-library/moreconversations-please? $\mathrm{ed}=14076$

---. "The Concept of 'Community' and 'Professional' Dance," Animated (Spring/Summer 2019). Accessed 10 Jan. 2021. https://www.communitydance.org.uk/DB/animatedlibrary/the-concept-of-community-and-professional-dance

Bauer, Eleanour. "Becoming Room, Becoming Mac, New Artistic Identities in the Transnational Brussels Dance Community." Maska 22 (2007): 58-67.

Bench, Harmony. Perpetual Motion: Dance, Digital Cultures and the Common. Minneapolis and London: University of Minnesota Press, 2020. https://doi.org/10.5749/j.ctvxw3p32

Blades, Hetty. "Affective Traces in Virtual Spaces: Annotation and Emerging Dance Scores," Performance Research 20.6 (2015): 26-34. https://doi.org/10.1080/13528165.2015.1111048

---. "Scoring Dance: The Ontological Impact of 'Choreographic Objects."' Unpublished PhD thesis. Coventry University, 2015. Accessed 31 January 2021. https://curve.coventry.ac.uk/open/file/200b5495-4d08-4228-8c532dda6fe53f1f/1/Hetty\%20Blades\%20PhD\%20Thesis_Redacted.pdf

---. "Scoring Choreographic Poetics," Choreographic Practices 6.2 (2015): 261-278. https://doi.org/10.1386/chor.6.2.261_1

---. "Preservation and Paradox: Choreographic Authorship in the Digital Sphere." Digital Echoes: Spaces for Intangible and Performance-Based Cultural Heritage. Eds. Sarah Whatley, Rosemary Cisneros, and Amalia Sabiescu. Cham: Palgrave Macmillan, 2018. 301-19. https://doi.org/10.1007/978-3-319-73817-8_16

Brown, Trisha. "Three Pieces." The Drama Review, 9.1 (1975): 26-32. https://doi.org/10.2307/1144964 
Burrows, Jonathan. A Choreographer's Handbook. Routledge: London and New York, 2010.

Coe, Katye. Interview with the author, online, December 2020.

D'Amato, Alison. "Performing Interpretation: Writing for the Body in Three Indeterminate Language Scores" CORD/SDHS Conference Proceedings: Writing Dancing/Dancing Writing. University of lowa, 13-16 November 2014.

Dakini Dance. 'Room/Roof Piece by Dakini Dance'. Performed by Valentina Polkovnikova, Wu Jialu, Elena, Zhanna Kromykh, Anastasia Potievskaya, Tian Xue, Uliana Ivanova, Yueming Wang, Lelia TahaBurt, Olga Merekina July 19 2020. Accessed 13 April 2020. https://www.youtube.com/watch?v=uRINMctzxa4

Detour Dance. Jukebox. Accessed $27 \quad$ Aug. 2020. https://www.detourdance.com/jukebox

Drouin Dance Center. "Drouin Dance Centre's Version of Room/Roof Piece by Trisha Brown Dance Company." May 28 2020. Accessed 13 April 2021. https://www.youtube.com/watch?v=1floju20TX4

Hearn, Jasmine. Interview with author, New York, 2018.

Kwan, SanSan. "When Is Contemporary Dance?" Dance Research Journal 49.3 (2017): 3852. https://doi.org/10.1017/S0149767717000341

McFee, Graham. Dance and the Philosophy of Action: A Framework for the Aesthetics of Dance. Hampshire: Dance Books, 2018.

Millard, Olivia. "What is the Score? Using Scores in Dance Improvisation." AusDance (2016). Accessed 10 January 2021. https://ausdance.org.au/articles/details/whats-thescore-using-scores-in-dance-improvisation

Pakes, Anna. Choreography Invisible: The Disappearing Work of Dance. New York: Oxford University Press, 2020. https://doi.org/10.1093/oso/9780199988211.001.0001

Salice, Alessandro. "Communities and Values. Dietrich von Hildebrand's Social Ontology." The Phenomenological Approach to Social Reality: History, Concepts, Problems. Eds. Alessandro Salice and Hans Bernhard Schmid. Switzerland: Springer, 2016. 237-257. https://doi.org/10.1007/978-3-319-27692-2_11

Sarco-Thomas, Malaika, Acosta, Sara Reyes and Grbic, Lucija. "Room/Roof Piece by Zoom May 2020." 31 May 2020. Accessed 13 April 2021. https://www.youtube.com/watch?v=GJMrqFUYRSY 
Sarco-Thomas, Malaika with University of Chester BA dance students. 'Room/Roof Piece with University of Chester BA Dance Students 2020' June 4 2020. Accessed 13 April 2021. https://www.youtube.com/watch?v=rSm8JxTt_u8

Seibert, Brian. "A D.I.Y. Dance for Your Home, From Yvonne Rainer." The New York Times. 24 March 2020. Accessed 27 Aug. 2020. https://www.nytimes.com/2020/03/24/arts/dance/yvonne-rainer-do-it-yourselfcoronavirus.html

---. "A Home Version of Trisha Brown's 'Roof Piece,' No Roof Required" The New York $\begin{array}{llllll}\text { Times. } & 7 & \text { April } 2020 . & \text { Accessed } 27 & \text { Aug. }\end{array}$ https://www.nytimes.com/2020/04/07/arts/dance/trisha-brown-roof-piece.html

Thomasson, Amie. "The Ontology of Social Groups." Synthese 196.12 (2019): 4829-4845. Accessed 31 January 2021. https://doi.org/10.1007/s11229-016-1185-y

UCLA Center for the Art of Performance. "The Choreographer's Scores: 2020." Accessed 13 April 2021. https://cap.ucla.edu/calendar/details/scores

Van Imschoot, Myriam. "Rests in Pieces." What's the Score: One Scores and Notations in Dance. $\quad$ Accessed 31 January 2021. http://olga0.oralsite.be/oralsite/pages/What\%27s_the_Score_Publication/

Vidrin, llya. "Reasoning in Relation: A Normative Inquiry of Dancing Together." PhD thesis. Coventry University, 2020. Accessed 31 January 2021. https://pureportal.coventry.ac.uk/en/studentTheses/reasoning-in-relation

Voris, Amy. "Forming, Returning and Deepening: Dance-making with the Processual Qualities of Authentic Movement." PhD thesis. University of Chichester, 2018. Accessed 31 January 2021. https://www.amyvoris.com/files/Amy Voris PhD thesis 'Forming, Returning and Deepening, Dance making with the Processual Qualities of Authentic Movement' (14 Nov 2019).pdf

---. Interview with author. Online. December 2020.

---. "perch." dorid heavy body. Accessed 10 January 2021. https://www.amyvoris.com/perch/

---. Written exchange with the author, April 2021.

Wenger, Etienne. "Communities of Practice: A Brief Introduction." https://scholarsbank.uoregon.edu/xmlui/bitstream/handle/1794/11736/A\%20brief\%2 0introduction\%20to\%20CoP.pdf 